\title{
DISCLAIMER
}

This report was prepared as an account of work sponsored by an agency of the United States Government. Neither the United States Government nor any agency thereof, nor any of their employees, makes any warranty, express or implied, or assumes any legal liability or responsibility for the accuracy, completeness, or usefulness of any information, apparatus, product, or process disclosed, or represents that its use would not infringe privately owned rights. Reference herein to any specific commercial product, process, or service by trade name, trademark, manufacturer, or otherwise does not necessarily constitute or imply its endorsement, recommendation, or favoring by the United States Government or any agency thereof. The views and opinions of authors expressed herein do not necessarily state or reflect those of the United States Government or any agency thereof.

\section{PRELIMINARY PERFORMANCE ESTIMATES AND VALUE ANALYSES FOR BINARY GEOTHERMAL POWER PLANTS USING AMMONIA-WATER MIXTURES AS WORKING FLUIDS}

\author{
C. J. Bliem
}

December 1983

EG\&G Idaho, Inc. 


\section{DISCLAIMER}

This report was prepared as an account of work sponsored by an agency of the United States Government. Neither the United States Government nor any agency Thereof, nor any of their employees, makes any warranty, express or implied, or assumes any legal liability or responsibility for the accuracy, completeness, or usefulness of any information, apparatus, product, or process disclosed, or represents that its use would not infringe privately owned rights. Reference herein to any specific commercial product, process, or service by trade name, trademark, manufacturer, or otherwise does not necessarily constitute or imply its endorsement, recommendation, or favoring by the United States Government or any agency thereof. The views and opinions of authors expressed herein do not necessarily state or reflect those of the United States Government or any agency thereof. 


\section{DISCLAIMER}

Portions of this document may be illegible in electronic image products. Images are produced from the best available original document. 
This report investigates the use of ammonia-water mixtures as working fluids in binary geothermal power generation systems. The available thermodynamic data is discussed and the methods of extrapolating this data to give the quantities needed to perform analyses of the system is given. Results indicated that for a system without a recuperator and with a working fluid which is 50 percent by mass of each constituent, the geofluid effectiveness (watt-hr/lbm geofluid) is 84 percent of that for the 50MW Heber Plant. The cost of generating electric power for this system was estimated to be 9 percent greater than for the Heber Plant. However, if a recuperator is incorporated in the system (using the turbine exhaust to preheat and partially boil the working fluid) the geofluid effectiveness becomes 102 percent of that for the Heber Plant, and the cost of electricity is 5-1/4 percent lower (relative to the Heber Plant) because of less expensive equipment resulting from lower pressure, better heat transfer, and less working fluid to handle for the ammonia-water plant. These results do not necessarily represent the optimum system. Because of uncertainty in thermodynamic properties, it was felt that detailed optimization was not practical at this point.

The present results do not reach the performance levels of some of the advanced plants using mixed hydrocarbon working fluids; those plants have been predicted to reach performance levels about 20 percent higher, and cost-ofelectricity levels about 13 percent lower than corresponding values for the Heber Plant. Further effort may, however, prove fruitful when better thermodynamic properties are obtained and a more detailed optimization is made. It was concluded, finally, that use of nonazeotropic mixtures of fluorocarbons as working fluids should be studied before expending further effort in the investigation of the ammonia-water mixtures. 


\section{TABLE OF CONTENTS}

SUMMARY . . . . . . . . . . . . . . . . . . . . . . . . . . .

1.0 INTRODUCTION . . . . . . . . . . . . . . . . . . . . 1

2.0 THERMODYNAMIC PROPERTIES OF AMMONIA-WATER MIXTURES . . . . . . . . . 3

2.1 Saturated Liquid and Vapor .............. . . 3

2.2 Subcooled-Liquid Region ................. . 4

2.3 Superheated Vapor Region . . . . . . . . . . . . . . . 4

2.4 Two-Phase Region ................. . . . . 4

3.0 SYSTEMS ANALYSIS AND ASSUMPTIONS . . . . . . . . . . . . . 6

4.0 CYCLE SCREENING AND PERFORMANCE ANALYSIS . . . . . . . . . . . 10

4.1 Unrecuperated Cycles, Dry Turbine Exhaust . . . . . . . . 10

4.2 Unrecuperated Cycles, Two-Phase Turbine Exhaust . . . . . . . 10

4.3 Recuperated Cycles . . . . . . . . . . . . . . 13

5.0 PRELIMINARY ECONOMIC ASSESSMENT . . . . . . . . . . . . . . 16

5.1 General Approach ................... 16

5.2 Heat Transfer Considerations . . . . . . . . . . . 17

5.3 Reference Plant Definition ............ . . . 18

5.4 Case 1 Economics Results .. . . . . . . . . . . . . . 19

5.5 Case 2 Economics Results ................. 21

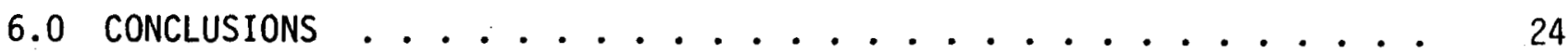

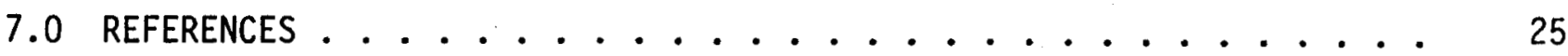

FIGURES

1. Diagram of a Simple Rankine Cycle . . . . . . . . . . . . 7

2. Diagram of a Power-Generation Cycle with Recuperation . . . . . . 8

3. Performance of Simple Rankine Cycle with Dry Turbine Expansion . . . 11

4. Performance of Rankine Cycles with Wet Turbine Expansions and with Recuperation ......................

5. Temperature-Heat Transferred Diagram for a Recuperated Ammonia-Water Power-Generation Cycle . . . . . . . . . . . . . 


\subsection{INTRODUCTION}

The performance of Rankine cycle binary systems for power generation using hydrothermal resources has been investigated, and those systems are now being used in a number of applications. The selection of a working fluid to maximize performance and/or minimize cost of production of electrical energy for a particular resource is a primary concern. The use of paraffin series hydrocarbons alone and in binary mixtures has been studied fairly extensively (see References 1,2). Milora and Tester (Reference 3 ) indicate that the performance of ammonia is superior at the high geofluid temperatures. The properties of ammonia are such that its use would result in a potential decrease in the size of required components and, therefore, a possible reduction in capital cost, relative to plants using hdyrocarbon working fluids.

A study for a liquid resource at a temperature as $10 \mathrm{w}$ as $280^{\circ} \mathrm{F}$ with an air-cooled condenser showed some advantages of ammonia over a hydrocarbon mixture (90 mass percent propane, 10 percent isopentane) and a pure hydrocarbon working fluid (isobutane). The performance of the ammonia system as measured by net geofluid effectiveness (net work produced per unit mass of geofluid) was inferior to either of the hydrocarbon systems; the geofluid effectiveness for ammonia was 94 percent of that for the pure fluid and 78 percent of that for the mixture. However, the sizes of components for the ammonia system were significantly smaller than those for either hydrocarbon system. For the same geofluid flow rate the heater/boiler tube surface area for the ammonia system was 82 percent of that for the pure hydrocarbon system and 50 percent of that for the mixture system. The condenser area for the ammonia system was 75 and 50 percent of the areas for the isobutane and the hydrocarbon mixture systems. The turbine outlet flow area for the ammonia system was 30 percent of that for the isobutane system and 48 percent of that for the mixture system. For the $280^{\circ} \mathrm{F}$ resource the pressures in the mixed hydrocarbon and ammonia systems were comparable (around 670 psia) while for the isobutane system the pressure was 250 psia.

At the higher resource temperature of interest in the present study, the maximum pressure in the ammonia system would go to impractically high 
limits. Mixtures of ammonia and water should, in general, maintain the advantageous characteristics of pure ammonia as discussed above, but should have lower pressures for a given resource temperature than pure ammonia. Therefore, it was decided to investigate the use of ammonia-water mixtures for the working fluid in a Rankine cycle for a hydrothermal resource at $360^{\circ} \mathrm{F}$. This report is a summary of that investigation.

Some properties of ammonia-water mixtures are available since interest in ammonia-water absorption refrigeration and heat pump systems have generated limited data. The information available is incomplete so that some of the necessary data was obtained by extrapolation from the existing information; the report discusses that process in detail. The report then discusses the configurations of the power generating systems for the ammonia-water mixtures, and the performance results are presented and analyzed. A simple cost-of-electricity analysis is included using a binary system similar to the Heber Plant as a reference plant. Finally, the results are summarized and conclusions drawn. 


\subsection{THERMODYNAMIC PROPERTIES OF AMMONIA-WATER MIXTURES}

Although thermodynamic properties exist for both water and ammonia, complete data is not available for mixtures of ammonia and water. A number of sources contain collections of some thermodynamic data for this mixture; however, these sources are most concerned with the liquid-vapor phase change and the resulting enthalpy change because the data was generated to analyze ammonia-water absorption refrigeration systems. One of the most complete sets of data is given in Research Bulletin No. 34 of the American Gas Association (Reference 4). This was the basis of the thermodynamic properties used in this study.

Reference 4 contains only a part of the thermodynamic data needed for cycle calculations. For pressures between 1 and $500 \mathrm{psia}$, and for mass fractions of ammonia between 0 and 1 , the dewpoint and bubble point temperature and enthalpy are given. Although the pressure range is adequate, data in the temperatures ranges for superheated vapor, liquidvapor, and subcooled liquid regions are needed for cycle analyses. Certain approximations have been made to obtain the required properties.

\subsection{Saturated Liquid and Vapor}

In the superheat region (near the saturation line) properties may deviate significantly from ideal gas properties because of the relatively high pressures encountered. It was assumed that the law of additive pressures held, and properties for the individual components were obtained from Reference 5 for water and Reference 6 for ammonia. This method predicts dewpoint temperatures and enthalpies which closely approximate those in Research Bulletin No. 34 (Reference 4) for mixtures if appropriate changes in base values for ammonia enthalpy are taken into account, and mixture enthalpies are are assumed to equal the mass weighted averages of the individual component enthalpies at their temperature and volumes (partial pressures) in the mixtures. For this work entropy was calculated in an analogous manner. 


\subsection{Subcooled-Liquid Region}

In the liquid region, it was assumed that the specific volume was the mass weighted average of the liquid specific volumes. This approximation is probably not totally correct because of the nonideality of this mixture, but its impact on the final results is quite small.

\subsection{Superheated Vapor Region}

In the superheated vapor region, the properties for the individual components were obtained from their individual property tables. The following mixing rules were applied to obtain the mixture properties:

1. Partial pressures were added to give the total pressure.

2. Enthalpies and entropies for the mixture were obtained by mass averaging the corresponding values for the pure constituents taken at their partial pressures and at the mixture temperature.

\subsection{Two-Phase Region}

No mixture data is available for the two-phase (liquid-vapor) region. The assumption has been made for this set of calculations that enthalpy (h) varies linearly with temperature for a constant pressure phase change. If this is true, the entropy $(s)$ can be calculated as a function of temperature $(T)$ and pressure $(p)$ as follows:

$$
\begin{aligned}
& d s=\frac{d h}{T}-\frac{v}{T} d p \\
& d s)_{p}=\frac{d h)_{p}}{T} \text { and } h_{p}=h_{b p}+\frac{h_{d p}-h_{b p}}{T_{d p}-T_{b p}} T \\
& \text { or } d h)_{p}=\frac{h_{d p}-h_{b p}}{T_{d p}-T_{b p}} d T=K d T .
\end{aligned}
$$




$$
\begin{aligned}
& d s=K \frac{d T}{T} \\
& s_{d p}-s=K \ln \frac{T d p}{T} \\
& \text { or } s=s_{d p}-K \ln \frac{T d p}{T} \\
& \text { where } K=\frac{h_{d p}-h_{b p}}{T_{d p}-T_{b p}} \text {, and subscripts bp and dp denote quantities }
\end{aligned}
$$

and the bubble and dew points.

The most suspect assumption made was that the enthalpy varied linearly with temperature in the two-phase region. This linearity, or lack of it, is very influential relative to the results of the analysis. For example, if the temperature-versus-enthalpy lines are curved, the heat exchanger pinch points will be moved, thereby influencing the flow ratio for the heat exchangers and, accordingly, the geofluid effectiveness. This behavior would be an area to explore in greater depth before pursuing further evaluation of ammonia-water mixtures as working fluids for the geothermal power-cycle application. 


\subsection{SYSTEMS ANALYSIS AND ASSUMPTIONS}

A plant producing electrical energy from a hydrothermal resource at $360^{\circ} \mathrm{F}$ was chosen as the reference for the comparison of an ammonia-water system with a state-of-the-art hydrocarbon system. Specifically, the 50MW Heber Plant being constructed in Imperial Valley, California was selected; it was designed to use geofluid at $360^{\circ} \mathrm{F}$, returning it at a temperature greater than $160^{\circ} \mathrm{F}$. Reference 7 describes and discusses approximate costs for an idealization of such a system.

A system using a water-ammonia mixture in this temperature range will involve a boiling (rather than a supercritical) cycle because of the critical properties of water and ammonia. The mixture will have a tendency to form moisture during an isentropic expansion, so it was thought that even without a recuperator some superheating of the working fluid would be needed to maintain low moisture levels in the turbine. Further analysis proved this superheating to be unnecessary (a 50 mass percent mixture, expanding from saturated vapor, had a moisture content of 8 percent in the turbine exhaust). However, the best system, which used a recuperator, was one with a superheater and a totally dry expansion in the turbine.

Figure 1 represents the simple Rankine cycle used in this analyses. As mentioned above, in some cases, no superheater was required. In most cases, the temperature of the vapor leaving the turbine is much higher than the temperature of the condensate leaving the condenser and pump, thus allowing for significant recuperation in the cycle. Figure 2 is a schematic diagram of a system with recuperation. In the Performance Analysis Section (Section 4.0) some systems with recuperators are explored.

The following assumptions were made for the analyses:

The geofluid supplied to the plant was liquid at $360^{\circ} \mathrm{F}$ at 300 psia. The geofluid leaving the plant was always at least $160^{\circ} \mathrm{F}$ to avoid silica precipitation in the reinjection system. 


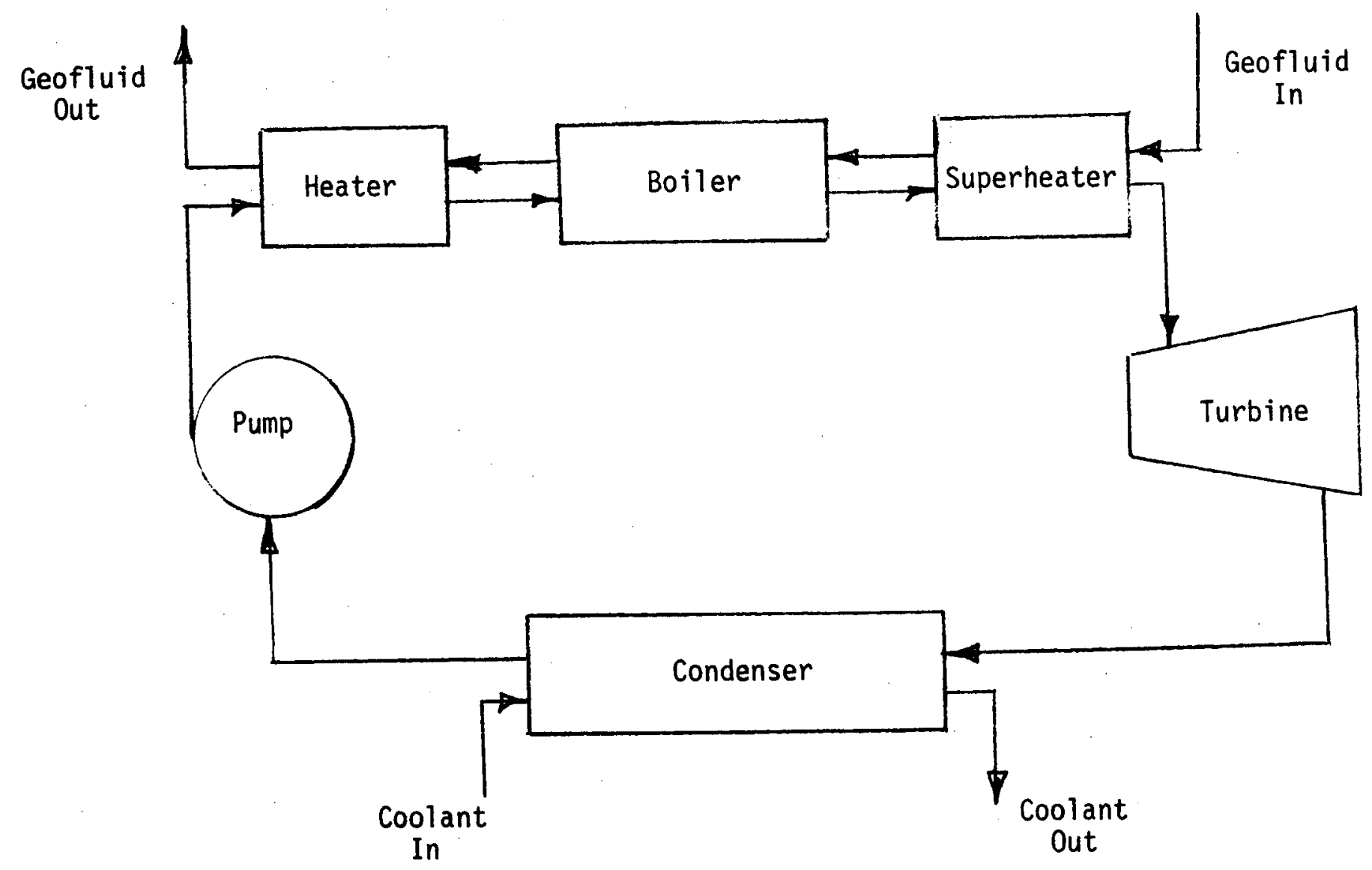

Figure 1: Diagram of a Simple Rankine Cycle 


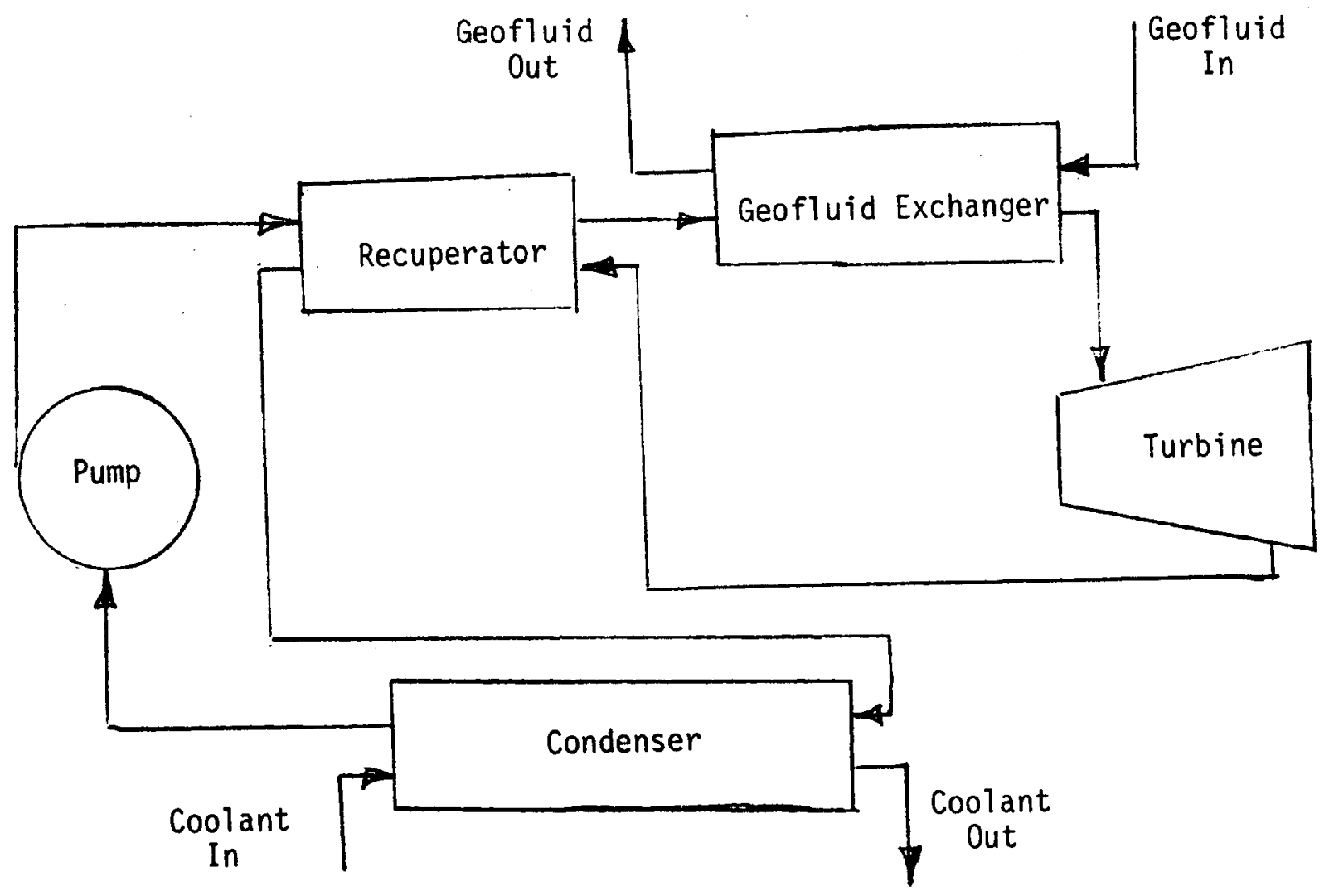

Figure 2: Diagram of a Power-Generation Cycle with Recuperation 
Cooling water was supplied to the system from a wet cooling tower. The wet bulb temperature was assumed to be $60^{\circ} \mathrm{F}$. With a $10^{\circ} \mathrm{F}$ approach assumed in the cooling tower, cooling water was supplied to the condenser at $70^{\circ} \mathrm{F}$. The parasitic power requirements for the cooling tower were approximated using the method outlined in References 1 and 2.

The pinch points in all heat exchangers were assumed to be $10^{\circ} \mathrm{F}$. Pressure drops in heat exchangers, piping, and control valves were neglected.

Working-fluid pump efficiency was taken to be 80 percent. The turbine efficiency used was 85 percent for dry expansions. When the expansions entered the two-phase region, this turbine efficiency was penalized 1 percent for each percent moisture in a given region. 


\subsection{CYCLE SCREENING AND PERFORMANCE ANALYSIS}

The cycle screening done to assess the potential of ammonia-water as a working fluid for binary geothermal cycles did not include a complete optimization. Rather, certain probing calculations were made to determine the general character of the performance map for this working fluid. First, dry turbine expansions were considered at different mixture ratios. Second, at the best mixture ratio, turbine expansions within the vapor dome were analyzed. Finally, the impact of using regeneration (utilizing the energy remaining in the turbine exhaust to preheat the working fluid) was assessed.

\subsection{Unrecuperated Cycles, Dry Turbine Exhaust}

Figure 3 illustrates the variation of geofluid effectiveness with mass fraction of ammonia for the case in which the state of the working fluid leaving the turbine is saturated vapor and the other parameters are as described in Section 3.0. The maximum geofluid effectiveness occurred near a mass fraction of 0.50 and was found to be roughly half that of the reference Heber Plant model. It is of interest to note that all of these cycles with mass fractions above 0.30 have condenser pressures which are greater than atmospheric pressure.

\subsection{Unrecuperated Cycles, Two-Phase Turbine Exhaust}

Based on results of the first set of calculations, the 0.50 mass fraction ammonia mixture was investigated at higher boiler pressures, for which conditions the expansions entered the two-phase region. Figure 4 shows the results of this study. As boiler pressure increased, the geofluid effectiveness increased to a maximum point at a boiler pressure of 280 psia. (The boiler pressure for the dry expansion was 80 psia.) The maximum geofluid effectiveness was found to be 84 percent that of the Heber model. In order to assure that the 0.50 mixture was near optimum, a similar curve for 0.30 mass 


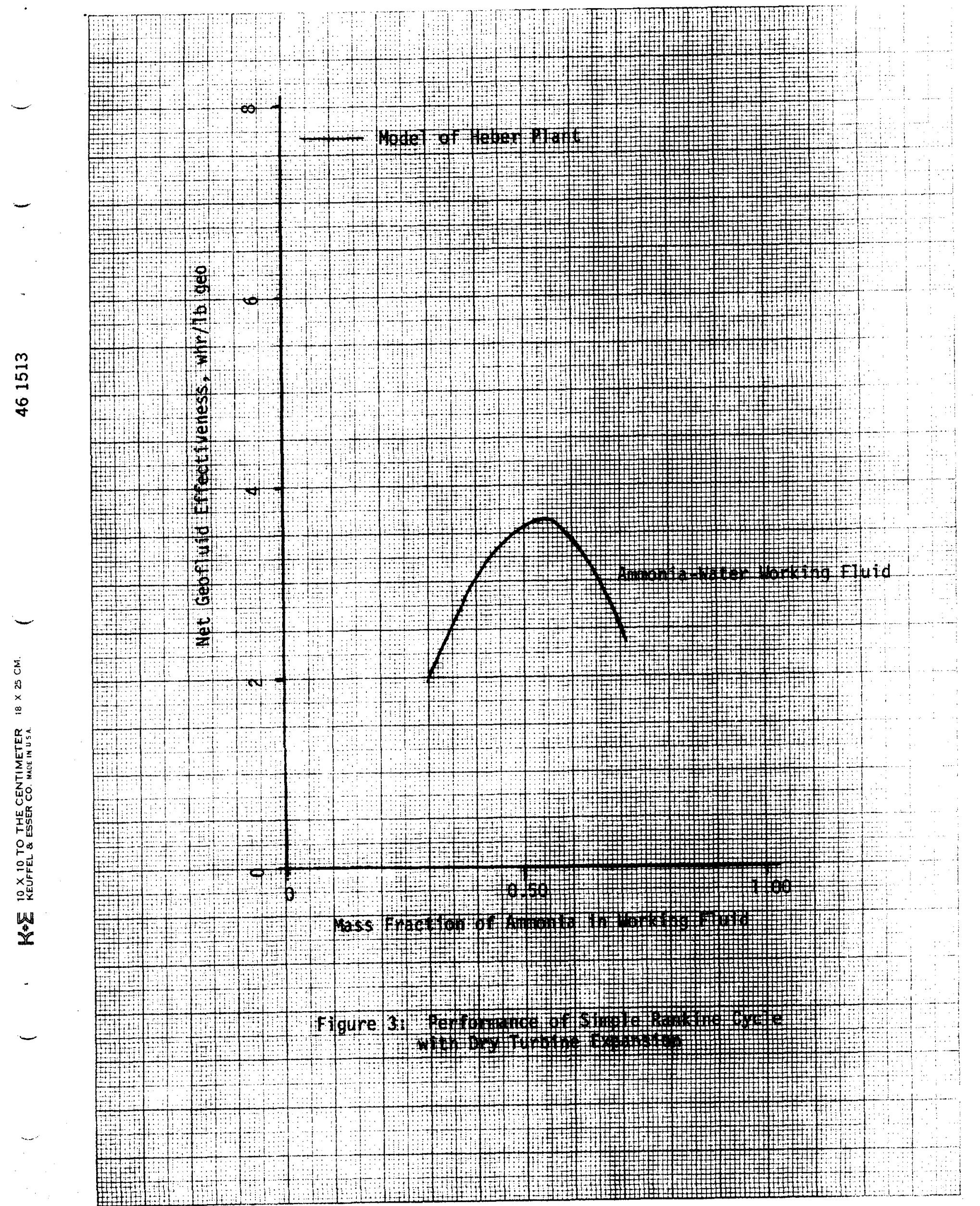




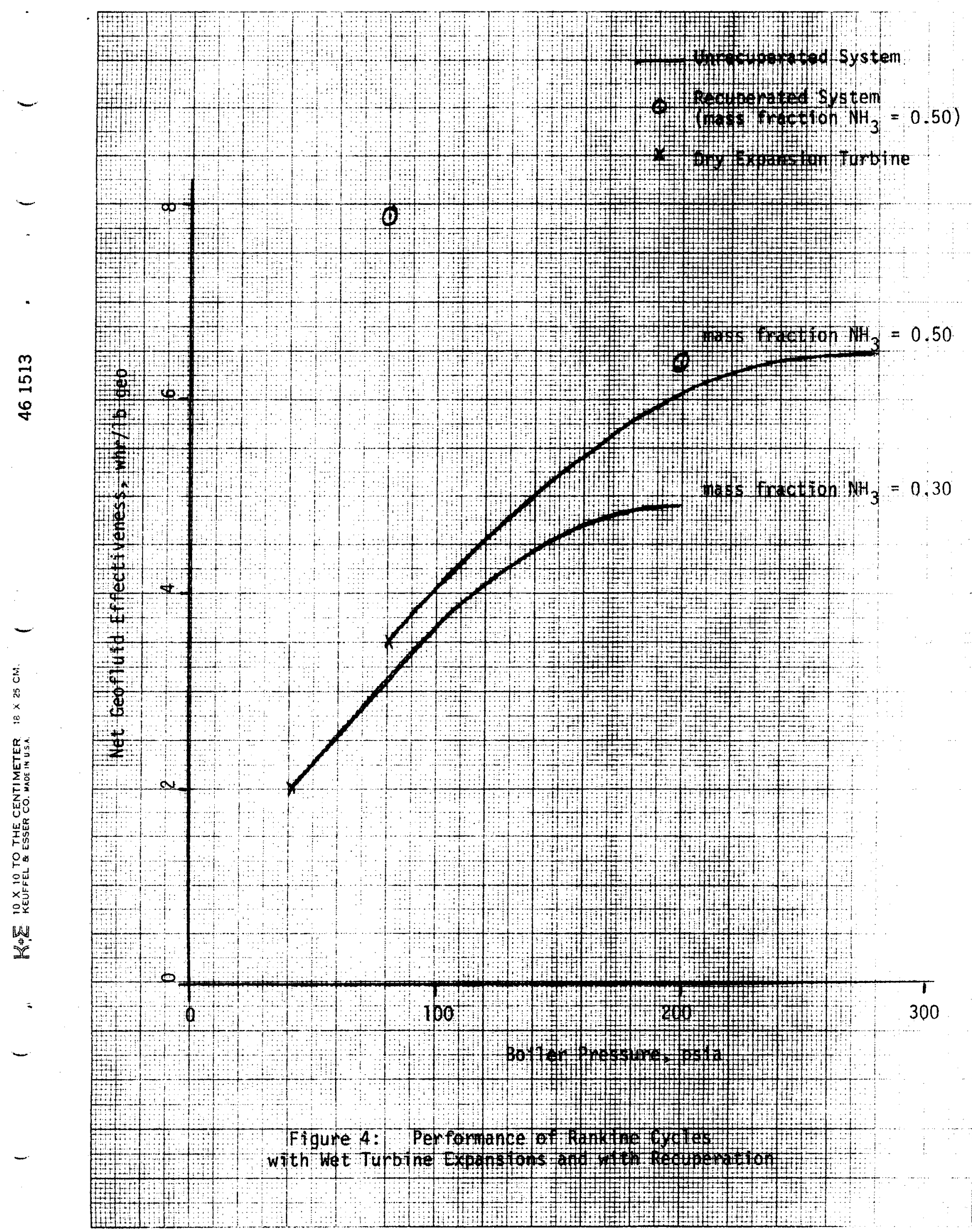


fraction ammonia is shown which is consistently lower than the 0.50 curve.

\subsection{Recuperated Cycles}

The third study considered the use of a recuperator with two of the 0.50-mass-fraction ammonia cycles. The circles on Figure 4 show these results. The best recuperated cycle was for the dry expansion at 0.50 mass fraction ammonia. Here, the geofluid effectiveness was approximately 2 percent higher than that of the reference Heber model.

Figure 5 shows a temperature-heat transferred diagram for the heat exchangers in the high effectiveness, recuperated cycle. The condenser, recuperator and geofluid/working fluid heat exchanger are all represented on a single diagram. This approach was taken because the condensing working fluid tied the condenser to the recuperator and the heated working fluid tied the recuperator to the geofluid/working fluid heat exchanger. The temperature differences between fluids in each exchanger are quite small, leading to high cycle thermal efficiencies. These small temperature differences, in general, would also lead to large heat exchangers. However, because the heat transfer coefficients for all mechanisms, except for condensing the working fluid, are high relative to those for a hydrcarbon mixture, the heat-exchanger sizes are not excessive. This point is illustrated in Section 5.0 in the cost analysis. The pressures are also low, relative to the hydrocarbon mixture, which also helps minimize the cost of exchangers.

The primary problem with the recuperated water-ammonia cycle is the fact that the geofluid would leave the system at the comparatively high temperature of $236^{\circ} \mathrm{F}$. This means that only 72 percent of the available energy would be recovered from the geofluid, as compared with a cycle with geofluid leaving at $160^{\circ} \mathrm{F}$. Further optimization relative to mass fraction of ammonia and boiler pressure could potentially allow recovery of more than the 72 percent, and improve the 





performance of the cycle. (Such changes to the cycle might also decrease the capital cost of the system by decreasing the condenser size.) Optimizations of this type have not been conducted. 


\subsection{PRELIMINARY ECONOMIC ASSESSMENT}

\subsection{General Approach}

A simplified screening method was used to compare one system with another by evaluating the effect of introducing the ammonia-water working fluid on the cost of power generation relative to a reference, state-of-the-art, geothermal power plant. The procedure, which lends itself to "ball parking" the value of various systems, is outlined in detail in Reference 7 and 8 . The basic approach involves estimating differences in capital and operating costs, as well as in plant performance, between the reference geothermal plant and the alternate designs. The specific procedure adopted relates these differences in cost and performance, all of which influence the real value of the plant modification, to the common denominator, cost of power.

To apply the method, the cost of electrical power for a "reference" plant must be known or assumed, and subdivided into a number of fractional contributions which include the specific areas being influenced by the design change. The fractional changes in cost for each of these areas (for which modifications are required) are estimated, along with the increase in electrical energy produced by the improved plant. If the modified design requires cost changes for $n$ contributions to the cost of electricity, and results in a fractional change in the annual energy produced, the fractional change in cost of electricity, relative to the reference design, can be written:

$$
\frac{\Delta \operatorname{COE}}{\operatorname{COE}}=\frac{\frac{-\Delta k W h}{k W h}+\sum^{n} \frac{\operatorname{COE}_{n}}{\operatorname{COE}}\left(\frac{\Delta C}{C}\right)_{n}}{\left(1+\frac{\Delta k W h}{k W h}\right)}
$$


Where: $\frac{\operatorname{COE}_{n}}{\mathrm{COE}}$ is the fractional contribution to cost of electricity (for the reference plant) of the $n$ 'th contribution for which a fractional change in cost, $\left(\frac{\Delta C}{C}\right)_{n}$, is required for the modified design. $\frac{\Delta \mathrm{kWh}}{\mathrm{kWh}}$ is the fractional change in electrical energy produced annually. Details of the development of this relationship are presented in Reference 7 .

References 7 and 8 document in detail the methods by which the numeral values of fractional contributions to the cost of electricity for the reference plant, ${ }^{C^{\prime} E_{n}}$, were determined for each component that was changed for the $\overline{\mathrm{COE}}$ modified plant. The method for calculation of the fractional changes in cost of a given component $\left(\frac{\Delta C}{C}\right)_{n}$ is also discussed in those references.

\subsection{Heat Transfer Considerations}

The primary difference between this evaluation and those discussed in the referenced documents (References 7 and 8 ) is in the selection of working fluids and in the heat transfer mechanisms as reflected by the overall heat transfer coefficients in individual heat exchangers. The following convective heat transfer coefficients were used to estimate the overall heat transfer coefficients. They were determined using Heat Transfer Research, Inc. (HTRI) methods and computer codes.

Substance

Ammonia-water

Geofluid

Cooling water

Hydrocarbon

Mixtures
Heat Transfer Mechanism

Heating liquid

Boiling

Heating vapor

Condensing

Cooling liquid

Heating liquid

Supercritical heating

Condensing
Convective Heat Transfer

Coefficient (Btu/hr $\mathrm{ft}^{2} \mathrm{~F}$ ) 
Fouling factors of $0.001 \mathrm{hr} \mathrm{ft}^{2} \mathrm{~F} / \mathrm{Btu}$ for the geofluid and cooling water, and $0.0005 \mathrm{hr} \mathrm{ft}^{2} \mathrm{~F} / \mathrm{Btu}$ the working fluid were used in the determination of overall heat transfer coefficients.

These assumptions lead to the following overall heat transfer coefficients:

System

Ammonia-water

Hydrocarbon mixture

\section{Component}

Heater

Boiler

Superheater

Condenser

Regenerative boiler

Regenerative heater

Heater

Condenser
Over Heat Transfer Coefficient (Btu/hr $\mathrm{ft}^{2 \circ} \mathrm{F}$ )

250

300

250

90

185

210

125

125

Note that the ammonia-water system provides higher heat transfer coefficients for the geothermal heat exchangers than does the hydrocarbon mixture system because of the better transport properties of the ammonia system, and because of the superiority of boiling heat-transfer characteristics as compared with single phase heat transfer. For the condenser the situation is reversed because of the much larger condensing temperature range of the ammonia-water mixture compared to the hydrocarbon mixtures.

\subsection{Reference Plant Definition}

The reference plant used in this analysis was a representation of the Heber 50MW geothermal plant as defined in Reference 7 . The basic definition of the reference plant is:

- 50 megawatt net plant output

- Working fluid - 0.88 isobutane/0.12 isopentane (by mass)

- Heater pressure - 580 psia 
- Heater pinch point - $10^{\circ} \mathrm{F}$

- Cocurrent or pot condensing with $10^{\circ} \mathrm{F}$ pinch point

- Plant outlet geofluid temperature - $160^{\circ} \mathrm{F}$

- No regenerative preheating (no turbine exhaust recuperator)

This reference plant was chosen because it represents a current state-of-the-art binary plant, and because it has been used previously as a reference for the comparisons of other innovative concepts.

Two systems are compared with the reference plant. The first case considers the unrecuperated ammonia-water plant which had the greatest geofluid effectiveness as shown in Section 3.0. The second case considers the recuperated ammonia-water plant with the highest effectiveness. The systems were sized to have the same geofluid flow rate as the reference plant. This approach results in identical costs associated with the field and geofluid distribution system.

\subsection{Case 1 Economics Results}

The basic definition of the plant in Case 1 follows:
- $\quad 41.9$ megawatt net plant power
- Working fluid-0.50 ammonia/0.50 water (by mass)
- Heater pressure - 280 psia
- Heater pinch points - $10^{\circ} \mathrm{F}$
- Countercurrent condensing with $10^{\circ} \mathrm{F}$ pinch points
- Plant outlet geofluid temperature - $184.2^{\circ} \mathrm{F}$
- No regenerative preheating (no turbine exhaust recuperator)
- Turbine expansion into the moisture region to an exit moisture of 7 percent

Table 5.1 presents a tabular summary of the economic evaluation of this case. Although the geofluid effectiveness of the Case 1 system was estimated to be 16 percent lower than that of the reference plant, the final cost of power was predicted to be only 9 percent higher than for the reference plant, because of reduction in capital costs for a number of components. The heater cost is lower than that of 
Table 5.1. Contributions to Change in Cost of Electricity for Case 1 (Best Ammonia/Water System Without Recuperator)

\begin{tabular}{|c|c|c|c|}
\hline Contribution & $\left(\frac{\Delta C}{C}\right)_{n}$ & $\frac{\mathrm{COE}_{n}}{\mathrm{COE}}$ & $\frac{\Delta M i l 1 \mathrm{~s} / \mathrm{kWh}}{\mathrm{Mi} 1 \mathrm{~s} / \mathrm{kWh}}$ \\
\hline$\frac{\Delta k W h}{k W h}$ & -0.1616 & 1.0 & +0.1927 \\
\hline Cooling water makeup & -0.0506 & 0.02 & -0.0088 \\
\hline Heater & -.471 & 0.038 & -0.213 \\
\hline $\begin{array}{l}\text { Miscellaneous working } \\
\text { fluid components }\end{array}$ & -0.803 & 0.034 & -0.0324 \\
\hline Turbine & -0.721 & 0.015 & -0.0129 \\
\hline Turbine piping & -0.568 & 0.0084 & -0.0057 \\
\hline Generator and structure & -0.116 & 0.0315 & -0.0044 \\
\hline Condenser & +0.455 & 0.025 & +0.0136 \\
\hline Cooling tower, pump, etc. & -0.0506 & 0.032 & -0.0019 \\
\hline Indirect capital & -0.0543 & 0.42 & -0.0272 \\
\hline & & TOTAL $\frac{\triangle \mathrm{COE}}{\mathrm{COE}}$ & +0.0917 \\
\hline
\end{tabular}


the reference case because of higher a heat transfer coefficient and a lower heat load. The condenser cost for the ammonia system is higher than for the reference case because of the lower heat transfer coefficient; the turbine and working-fluid evaporators are lower in cost, reflecting the lower working-fluid flow rate for a given geofluid flow. The cooling tower and cooling water make-up costs are approximately the same for the two systems because of the equivalent magnitudes of heat rejected.

\subsection{Case 2 Economics Results}

The second case is more promising. The basic plant is defined as follows:

- $\quad 50.96$ megawatts net plant power

- Working fluid-0.50 ammonia/0.50 water (by mass)

- Heater pressure - 85 psia

- Heater pinch points - $10^{\circ} \mathrm{F}$

- Countercurrent condenser with $10^{\circ} \mathrm{F}$ pinch points

- Recuperator with $10^{\circ} \mathrm{F}$ pinch points (Note that there is partial condensation of the working fluid in the recuperator.)

- Expansion in the turbine is dry, ending on the saturation line.

Table 5.2 presents a summary of the economic evaluation of Case 2. The performance of the system indicates a 2 percent increase over the reference case. The cost of power is decreased by nearly 5 percent compared to the reference case. A large portion of the decrease in cost of power (2 percent) comes from the decreased heat rejected and the decreases in cooling-tower and cooling-water-makeup costs. Because the recuperator accomplishes a large fraction of the functions accomplished by both the heater and the condenser in the reference case, the individual heat-exchanger effects cannot be separated. The net effect of the heat exchangers on the cost of power is to produce a 1 percent decrease. The turbine, generator, and piping for the 
Table 5.2. Contributions to Change in Cost of Electricity of Case 2 (Best Ammonia/Water System with Recuperator)

\begin{tabular}{|c|c|c|c|}
\hline Contribution & $\left(\frac{\Delta C}{C}\right)_{n}$ & $\frac{\operatorname{COE}_{n}}{\operatorname{COE}}$ & $\frac{\Delta M i 11 \mathrm{~s} / \mathrm{kWh}}{\mathrm{Mi} 11 \mathrm{~s} / \mathrm{kWh}}$ \\
\hline$\frac{\Delta k W h}{k W h}$ & 0.0193 & 1.0 & -0.0189 \\
\hline Cooling water makeup & -0.4481 & 0.02 & -0.0088 \\
\hline Heater & -0.9130 & 0.038 & -0.0340 \\
\hline $\begin{array}{l}\text { Miscel laneous working } \\
\text { fluid components }\end{array}$ & -0.5405 & 0.034 & -0.0181 \\
\hline Turbine & +0.3880 & 0.015 & +0.0057 \\
\hline Turbine piping & +0.2690 & 0.0084 & +0.0023 \\
\hline Generator and structure & +0.0133 & 0.0315 & +0.0004 \\
\hline Condenser & -0.0165 & 0.025 & -0.0004 \\
\hline Recuperator & 0.8234 & 0.025 & -0.0004 \\
\hline Recuperator installation & 0.80 & 0.0019 & +0.0015 \\
\hline Cooling tower, pump, etc. & -0.4481 & 0.032 & -0.0140 \\
\hline Indirect capital & -0.0387 & 0.42 & -0.0159 \\
\hline & & TOTAL $\frac{\triangle \mathrm{COE}}{\mathrm{COE}}$ & -0.0516 \\
\hline
\end{tabular}


system are larger, resulting in a 1 percent increase, while the remaining working-fluid components give about a 2 percent decrease in cost of power because of the small requirements for working fluid pumping and flow in the ammonia-water system. 


\subsection{CONCLUSIONS}

The primary conclusion of this work is that the use of an ammonia-water mixture as a working fluid in a cycle with recuperation will. increase the performance of that system a few percent over a system representing the 50MW Heber Plant, and that it will decrease the cost of power by more than 5 percent. These improvements are smaller than predicted for some paraffin base hydrocarbon mixtures explored previously, but of significance is that much lower pressures are needed for the ammonia system. These results were not obtained from a systematic optimization; greater gains might be predicted for the ammonia-water system with further optimization. Additionally, the ammonia-water working fluid would be lower in cost and flammability than would hydrocarbon working fluids, but would be more toxic.

Second, the use of ammonia-water systems without recuperation of the energy in the turbine exhaust is not of sufficient promise to consider further.

Third, prior to further analysis, a better estimate of thermodynamic properties is needed. Some of the present results are influenced by the extrapolation procedure needed for the present data (for example, assuming a linear relationship between enthalpy and temperature during condensation).

Overall, it is recommended that an avenue to pursue, relative to improved working fluids, before expending further effort toward the investigation of the ammonia-water mixtures is to investigate the use of non-azeotropic fluorocarbon mixtures as working fluids for binary geothermal cycles. These mixtures may show some of the performance and cost-of-power benefits predicted for the mixed-hydrocarbon working fluids in References 1, 2, and 7, while at the same time, eliminating plant capital and operating costs introduced because of the flammability of the hydrocarbons. 


\subsection{REFERENCES}

1. 0. J. Demuth, "Analyses of Mixed Hydrocarbon Binary Thermodynamic Cycles for Moderate Temperature Geothermal Resources", EGG-GTH-5753, February 1981.

2. 0. J. Demuth and R. J. Kochan, "Analyses of Mixed Hydrocarbon Binary Thermodynamic Cycles for Moderate Temperature Geothermal Resources Using Regeneration Techniques", EGG-GTH-5710, December 1981.

3. Stanley L. Milora and Jefferson W. Tester, "Geothermal Energy as a Source of Electric Power," the MIT Press, Cambridge, Massachusetts, 1976.

4. R. A. Macriss, B. E. Ealcia, R. T. Ellington, and J. Huebler, "Physical and Thermodynamic Properties of Ammonia-Water Mixtures", Research Bulletin No. 34, Institute of Gas Technology, Chicago, I11 inois, September 1964.

5. J. H. Keenan, F. G. Keyes, P. G. Hill, and J. G. Moore, Steam Tables (English Units), John Willey and Sons, New York, 1969.

6. Table of Thermodynamic Properties of Ammonia, National Bureau of Standards, Circular No. 142, Washington, DC, 1923.

7. 0. J. Demuth and J. F. Whitbeck, "Advanced Concept Value Analysis for Geothermal Power Plants", EGG-GTH-5821, March 1982.

8. 0. J. Demuth, "Effects of Vaporizer and Evaporative-Condenser Size on Geofluid Effectiveness and Cost of Electricity for Geothermal Binary Plants", EGG-GTH-6376, October 1983. 